\title{
Ciclo biológico de Calacarus heveae Feres, 1992 (Acari, Eriophyidae) $)^{1}$
}

\author{
Noeli Juarez Ferla² \\ Gilberto José de Moraes 3,4
}

\begin{abstract}
Biological cycle of Calacarus heveae Feres, 1992 (Acari, Eriophyidae). Calacarus heveae Feres, 1992 is an Eriophyidae mite described from rubber tree (Hevea brasiliensis Muell. Arg.) in the northwest region of the State of São Paulo. This mite prefers the adaxial face of the folioles and it can reduce the brightness of the leaves, turning them progressively yellow and brownish, and consequently premature fall. The aim of this work was to study the biology of $C$. heveae in laboratory, on detached rubber tree folioles. The study was conducted at $28 \pm 1{ }^{\circ} \mathrm{C}$ in the photophase $(12 \mathrm{~h})$, $25 \pm 1{ }^{\circ} \mathrm{C}$ in the dark phase (12h), and $90 \pm 5 \%$ relative humidity. The study was initiated with a total of 59 eggs. The average duration of egg, larva and nymph stages was 5.8, 2.0 and 1.4 days, respectively. The period from egg to adult lasted 9.3 days, and the average periods of pre-oviposition, oviposition and post-oviposition, 1.8, 6.1 and 1.2 days, respectively. The average longevity of the adult male was ca. 4.0 days, while the longevity adult female was about 8.4 days. The average daily oviposition rate was 2.3 egg per female while the average fecundity was 16.2 eggs per female.
\end{abstract}

Keywords. Acari; biology; Calacarus heveae; Eriophyidae; rubber tree.

\section{INTRODUÇÃO}

Calacarus heveae Feres, 1992 é um eriofídeo descrito de espécimes coletados em plantas de seringueira (Hevea brasiliensis Muell. Arg.) na região noroeste do Estado de São Paulo (Feres 1992). Esta espécie prefere a face adaxial dos folíolos, mas ocorre também na face abaxial, quando em altas populações, podendo causar perda do brilho, amarelecimento e bronzeamento dos folíolos e sua conseqüente queda prematura (FERES 2000). De acordo com VIEIRA \& GoMES (1999), que acompanharam a dinâmica populacional de C. heveae em Reginópolis, Estado de São Paulo, as maiores populações foram observadas no primeiro semestre do ano, coincidindo com o período de maior produção de látex. Os mesmos autores relataram que o ataque desta espécie pode provocar níveis de desfolha acima de 75\%. Segundo Feres (2000), alguns produtores de seringueira estimam que $C$. heveae ocasione perdas de até $30 \%$ na produção de látex de alguns clones de $H$. brasiliensis.

Este trabalho teve como objetivo estudar o ciclo biológico de $C$. heveae em condições de laboratório.

\section{MATERIAL E MÉTODOS}

Este estudo foi realizado no período de janeiro a maio de 2000. Inicialmente estabeleceu-se uma criação de manutenção de $C$. heveae com espécimes coletados em folhas de seringueira da Estação Experimental de Pindorama, do Instituto Agronômico de Campinas - IAC, no Estado de São Paulo. Para tanto, foram preparadas unidades de criação com folíolos do clone PB 260 coletados das plantações da Escola Superior de Agricultura "Luiz de Queiroz"/Universidade de São Paulo, Piracicaba - São Paulo. Os folíolos foram lavados em água destilada e postos com a face abaxial sobre um pedaço de esponja de náilon umedecida em bandejas de alumínio de 5 x 7 x $25 \mathrm{~cm}$, recobrindo as bordas dos folíolos com tiras de algodão hidrófilo. Para manter alta a umidade relativa, cada bandeja foi coberta com uma placa de vidro, deixando-se aberta uma fresta lateral de cerca de $1 \mathrm{~cm}$ para evitar a condensação de vapor d'água sobre os folíolos. Diariamente, adicionava-se água destilada à bandeja, para manter a esponja sempre úmida. Os ácaros foram transferidos com um pincel para novas unidades de criação quando os folíolos em que se encontravam começavam a

1. Parte de tese apresentada à Escola Superior de Agricultura “Luiz de Queiroz” (ESALQ/USP) no ano de 2001.

2. Museu de Ciências Naturais, Centro Universitário UNIVATES. 95900-000 Lajeado - RS, Brasil. Endereço eletrônico: njferla@fates.tche.br

3. Departamento de Entomologia, Fitopatologia e Zoologia Agrícola, Escola Superior de Agricultura "Luiz de Queiroz". 13418-900 Piracicaba-

SP, Brasil. Endereço eletrônico: gjmoraes@carpa.ciagri.usp.br

4. Bolsista do CNPq. 
amarelar. As bandejas foram mantidas em uma câmara climatizada a $25,5 \pm 1^{\circ} \mathrm{C}$, fotofase de 12 horas e umidade relativa de $90 \pm 5 \%$.

O estudo da biologia foi realizado com unidades de criação preparadas como descrito no parágrafo anterior, utilizando-se o mesmo clone de seringueira. Cada unidade foi então dividida em quadrados de aproximadamente $2 \mathrm{~cm}^{2}$ com o uso de tiras de lenço de papel, estabelecendo-se assim as unidades de criação para o estudo da biologia.

O estudo foi iniciado com ovos obtidos da seguinte forma. Inicialmente, 10 fêmeas foram transferidas da criação de manutenção para cada unidade de criação. Após um período de 12 horas, as unidades foram examinadas retirando-se as fêmeas daquelas unidades onde havia ocorrido a oviposição, assim como os ovos excedentes, deixando-se apenas 1 ovo por unidade. $O$ restante das arenas foi examinado novamente após outro período de 12 horas, repetindo-se o processo até que se obtivesse um total de 59 ovos. Cada unidade de criação foi examinada diariamente às 7, 12 e 17 horas, até que os ácaros atingissem o estádio adulto, quando foram então transferidos para novas unidades. Em cada exame, verificou-se o estádio de desenvolvimento em que o ácaro se encontrava. Na fase adulta, observações foram realizadas diariamente às 14 horas, para se verificar o número de ovos postos e a sobrevivência dos ácaros. Nesta parte do estudo, apenas fêmeas não fecundadas foram utilizadas, devido a dificuldade em se promover a fecundação destas dada a forma de transferência indireta de esperma dos ácaros desta família e a semelhança muito grande de machos e fêmeas.

As unidades de criação foram mantidas em câmara climatizada com fotoperíodo de 12 horas e umidade relativa de $90 \pm 5 \%$. Na tentativa de imitar as condições ambientais do campo, a temperatura foi mantida a $28 \pm 1{ }^{\circ} \mathrm{C}$ na fotofase e $23 \pm 1^{\circ} \mathrm{C}$ na escotofase.

Após a morte, todos os adultos foram montados em meio modificado de Berlese (Amrine \& MANson 1996) para sexagem ao microscópio.

Os espermatóforos utilizados para observação foram obtidos nas colônias de manutenção de C. heveae. Para tanto, os folíolos com ácaros foram fixados por uma semana no fixador Karnovsky modificado (Glutaraldeído 2,5\%, formaldeído 2,5\% em tampão, cacodilato de sódio 0,05 M, Ph 7,2). Em seguida, foi feita a pós-fixação em tetróxido de ósmio (1\% em tampão cacodilato de sódio $0,05 \mathrm{M}, \mathrm{Ph} 7,2$ ) por 2 horas, seguida da secagem ao ponto crítico para posterior metalização com ouro (210 segundos). Para determinar a forma dos espermatóforos de $C$. heveae, foram feitas observações ao microscópio eletrônico de varredura (Zeiss DSM 940).

\section{RESULTADOS}

\section{Características biológicas dos estádios imaturos.}

A duração das diferentes fases e a viabilidade de C. heveae são apresentadas na Tabela I.

O período médio de incubação do ovo foi de 5,8 dias e a viabilidade deste estádio foi de $95 \%$. Os ovos são esbranquiçados quando recém-postos, passando a translúcidos após algumas horas. Arredondados (cerca de $75 \mu \mathrm{m}$ de diâmetro) e achatados, ficam aderidos ao substrato, sendo muito difícil manuseá-los.

Horas antes da eclosão, é possível visualizar movimentos da larva através do córion translúcido. A eclosão ocorreu, na maioria das vezes, na parte da manhã, logo após haver a passagem da temperatura de $23^{\circ} \mathrm{C}$ para $28^{\circ} \mathrm{C}$. A emergência durou cerca de 20 minutos.

A duração do estádio de larva foi de 2,0 dias, enquanto que o de ninfa, 1,4 dias. A viabilidade conseguida nos estádios de larva e ninfa foi $96 \%$ e $98 \%$, respectivamente.

A larva, que apresenta comprimento de 90-110 $\mu \mathrm{m}$, inicia a alimentação na região próxima ao córion do ovo do qual emergiu. Após algumas horas, começa a se formar um friso de cera longitudinal na parte mediana do dorso do opistossoma. A mobilidade é normal até pouco antes da próxima ecdise. Para a ecdise, o ácaro fixa o telossoma no substrato, rompendo o exoesqueleto na região mediana do escudo prodorsal. A ecdise dura cerca de 15 minutos.

As ninfas medem 140-160 $\mu \mathrm{m}$. Neste estádio, três frisos de cera percorrem longitudinalmente o dorso do opistossoma. Em relação à ecdise, a ninfa se comporta de forma semelhante à larva. O processo de ecdise demora cerca de 25 minutos.

O período de ovo a adulto durou cerca de 9,7 dias para as fêmeas e 9,0 dias para os machos.

Tabela I. Duração e viabilidade (machos e fêmeas) das diferentes fases imaturas de Calacarus heveae, em dias, criados em folíolos de seringueira da variedade PB 260 a $28 \pm 1{ }^{\circ} \mathrm{C}$ na fotofase e $25 \pm 1{ }^{\circ} \mathrm{C}$ na escotofase, fotofase de 12 horas e umidade relativa de $90 \pm 5 \%$, no período de janeiro a maio de 2000 .

\begin{tabular}{lccc}
\hline Estádio de desenvolvimento & Média \pm EPM & Viabilidade (\%) & N \\
\hline Ovo & $5,8 \pm 0,1$ & 95 & 57 \\
Larva & $2,0 \pm 0,001$ & 96 & 55 \\
Ninfa & $1,4 \pm 0,05$ & 98 & 54 \\
Ovo-adulto (Fêmeas e Machos) & $9,3 \pm 0,09$ & 91,5 & 54 \\
Ovo-adulto (Fêmeas) & $9,7 \pm 0,02$ & - & 26 \\
Ovo-adulto (Machos) & $9,0 \pm 0,02$ & - & 14 \\
\hline
\end{tabular}

EPM: Erro padrão da média.

$\mathrm{N}$ : Número de indivíduos observados.

\section{Características biológicas do estádio adulto.}

Dos ovos postos pela geração estudada, foram obtidos 274 adultos, todos machos. Isso indica a ocorrência de partenogênese arrenótoca, de vez que as fêmeas da geração estudada foram mantidas em arenas sem presença de machos.

O adulto recém emergido é cinza brilhante, passando a cinza opaco com o passar do tempo. Inicialmente, movimenta-se intensamente mas, ao iniciar a alimentação, diminui o deslocamento, permanecendo por longo tempo numa determinada área. Os adultos medem entre 190-230 $\mu \mathrm{m}$.

Os adultos apresentam deposição de cera sobre o escudo prodorsal e em 3 linhas dorso-longitudinais do opistossoma (Fig. 1). 


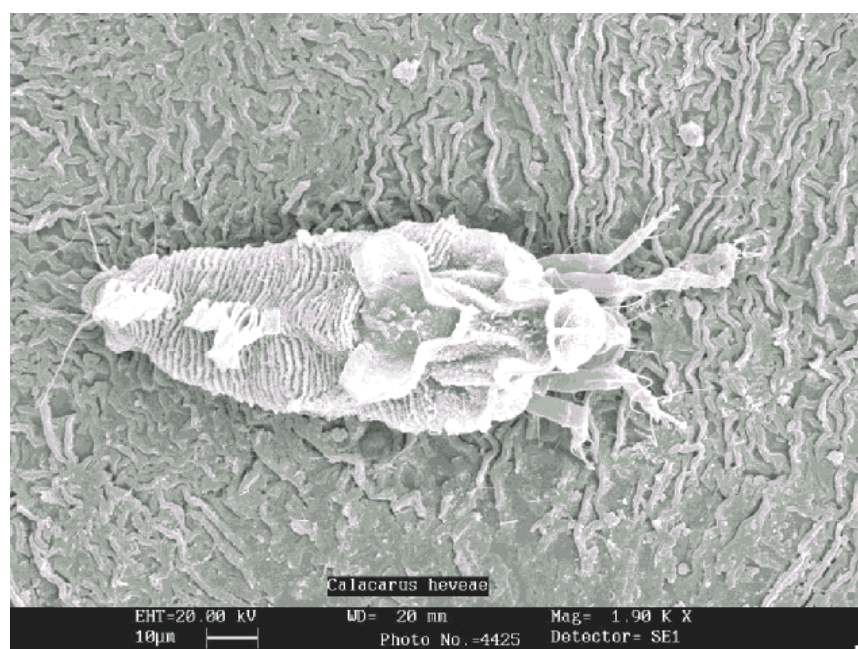

Fig. 1. Adulto de Calacarus heveae.

O período de pré-oviposição de $C$. heveae durou cerca de 1,8 dias; a oviposição, 6,1 e a pós-oviposição, 1,2 dias (Tabela II).

A longevidade média do macho adulto foi de aproximadamente 4,0 dias, enquanto a da fêmea adulta foi de cerca de 8,4 dias.

A oviposição média diária foi de 2,3 ovos por fêmea. A fecundidade média foi de 16,2 ovos por fêmea. Não se constatou nenhuma preferência por sítios determinados de oviposição sobre a superfície da folha.

A duração total de ovo até a morte dos indivíduos foi de aproximadamente 16 dias, sendo que os machos duraram, em média, cerca de 13,0 dias e as fêmeas, 17,8 dias. A razão sexual obtida foi de $65 \%$ de fêmeas.

A Fig. 2 mostra a variação de oviposição média diária de $C$. heveae. Observou-se que esta variou ao longo de um patamar nos primeiros 12 dias de oviposição, decrescendo a partir de então.

O espermatóforo de C. heveae foi visualizado através de

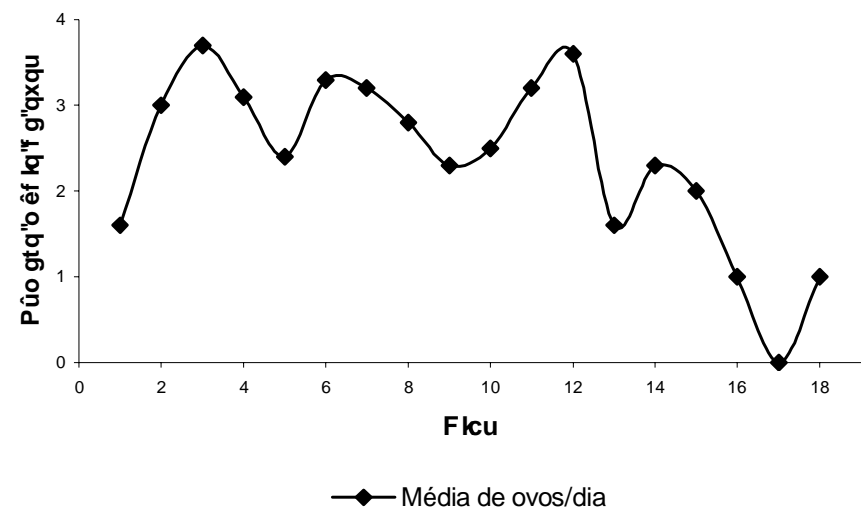

Fig. 2. Oviposição média diária de fêmeas não fecundadas de Calacarus heveae, a $28 \pm 1{ }^{\circ} \mathrm{C}(12 \mathrm{~h})$ na fotofase e $25 \pm 1{ }^{\circ} \mathrm{C}(12 \mathrm{~h})$ na escotofase e umidade relativa de $90 \pm 5 \%$ em folíolos de seringueira da variedade $\mathrm{PB}$ $260(\mathrm{~N}=16)$, no período de janeiro a maio de 2000.

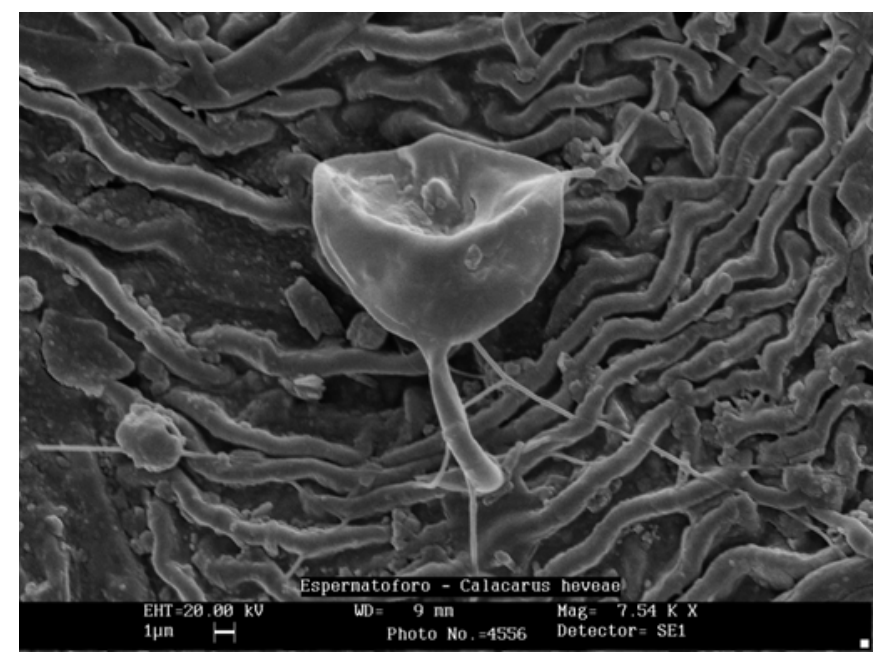

Fig. 3. Espermatóforo de Calacarus heveae obtidos em colônias de laboratório.

microscopia eletrônica, apresentando a cabeça em forma de taça, medindo aproximadamente $12 \mu \mathrm{m}$ de lado na extremidade mais dilatada. Esta é presa a um pedúnculo, medindo aproximadamente $8 \mu \mathrm{m}$ de comprimento, cuja base é fixada no folíolo (Fig. 3). Não foi possível visualizar o endoespermatóforo.

\section{DISCUSSÃO}

As únicas informações sobre a morfologia de $C$. heveae até hoje disponíveis foram apresentadas na descrição original da espécie (Feres 1992), que trata apenas da fase adulta. Os dados aqui apresentados sobre a morfologia deste ácaro complementam aquelas informações, especialmente no que se refere aos estádios imaturos e à forma do espermatóforo. $\mathrm{O}$ espermatóforo de $C$. heveae apresenta tamanho e forma muito semelhantes ao que se conhece até agora para outros eriofídeos (OldField et al. 1970; OldField \& Michalska 1996).

Informações sobre o ciclo biológico de espécies de Calacarus Keifer, 1940 são escassas na literatura. Os estudos

Tabela II. Longevidade e reprodução de Calacarus heveae, a $28 \pm 1{ }^{\circ} \mathrm{C}$ (12h) na fotofase e $25 \pm 1{ }^{\circ} \mathrm{C}$ (12h) na escotofase e umidade relativa de $90 \pm 5 \%$ em folíolos de seringueira da variedade PB 260 no período de janeiro a maio de 2000 .

\begin{tabular}{lcc}
\hline Estádio de desenvolvimento & Média \pm EPM & $\mathrm{N}$ \\
\hline Pré-oviposição & $1,8 \pm 0,16$ & 26 \\
Oviposição & $6,1 \pm 0,9$ & 26 \\
Pós-oviposição & $1,2 \pm 0,2$ & 26 \\
Longevidade da fêmea adulta & $8,4 \pm 0,9$ & 26 \\
Longevidade do macho adulto & $4,0 \pm 0,3$ & 14 \\
Longevidade total da fêmea & $17,8 \pm 1,0$ & 26 \\
Longevidade total do macho & $13,0 \pm 0,32$ & 14 \\
Ovos/fêmea/dia & $2,3 \pm 0,18$ & 26 \\
Ovos/fêmea & $16,2 \pm 3,2$ & 26 \\
\hline
\end{tabular}

EPM: Erro padrão da média.

$\mathrm{N}$ : Número de indivíduos observados. 
até hoje realizados referem-se a Calacarus citrifolii (Keifer, 1955), espécie conhecida de citros na África do Sul (VAN DeR Merwe \& Coates 1965) e Calcarus carinatus (Green, 1890), uma das mais importantes pragas da cultura de chá no sul da Ásia (Jeppson et al. 1975).

Diversas foram as tentativas iniciais até se conseguir estabelecer uma colônia de manutenção de $C$. heveae em laboratório. Inicialmente, as maiores dificuldades se relacionaram ao fato de, praticamente, todos os ácaros coletados em Itiquira e levados ao laboratório estarem infectados pelo fungo Hirsutella thompsonii Fisher. TANZINI et al. (2000) haviam relatado a ação deste patógeno sobre $C$. heveae. Desta forma, foi necessário buscar populações de outras localidades (Pindorama, Estado de São Paulo), na época não infectadas, para iniciar uma colônia de manutenção deste ácaro. Posteriormente, verificou-se que a colônia só podia ser mantida adequadamente após se promover o aumento da umidade relativa, cobrindo-se quase que totalmente a bandeja que continha as unidades de criação com uma placa de vidro. Outro desafio foi o reconhecimento do ovo de $C$. heveae que, por ser bastante achatado e relativamente grande em relação ao tamanho da fêmea, passou despercebido nas observações iniciais.

As informações das fases imaturas conseguidas com $C$. heveae são semelhantes àquelas encontradas por VAN DER MERWE \& CoATEs (1965) que estudaram a biologia C. citrifolii, exceto para o estádio de ninfa que foi 2 a 3 vezes mais longo para C. citrifolii. Os mesmos autores relataram oviposição média diária de 1,1 ovos por fêmea e longevidade média de 10 dias para fêmeas adultas.

Quanto a C. carinatus, cuja biologia foi estudada por KING (1937), o período de ovo a adulto foi de 10 a 12 dias, um pouco superior ao período observado com $C$. heveae, que foi de aproximadamente nove dias. Além disso, a oviposição média de C. carinatus foi de 21 ovos/fêmea num período de 10 a 13 dias, enquanto que para $C$. heveae foram 16 ovos/fêmea, num período médio de seis dias.
Agradecimento. Às empresas Plantações Edouard Michellin Ltda. e Triângulo Agro-Industrial Ltda., pelo financiamento do projeto. Ao Conselho Nacional de Desenvolvimento Científico e Tecnológico (CNPq), pela concessão de bolsa para a realização do doutorado do primeiro autor.

\section{REFERÊNCIAS}

Amrine J. R. \& D. C. M. Manson. 1996. Preparation, Mounting and Descriptive Study of Eriophyoid Mites, p. 383-321. In: E. E. LINDQUIST; M. W. SAbelis \& J. BRuin (eds.) Eriophyoid Mites: their biology, natural enemies and control. Amsterdam, Elsevier, xxxiii+643p.

Feres, R. J. F. 1992. A new species of Calacarus Keifer (Acari, Eriophyidae, Phyllocoptinae) from Hevea brasiliensis Muell. Arg. (Euphorbiaceae) from Brazil. International Journal of Acarology 18 (1): 61-65.

Feres, R. J. F. 2000. Levantamento e observações naturalísticas da acarofauna (Acari, Arachnida) de seringueiras cultivadas (Hevea spp., Euphorbiaceae) no Brasil. Revista Brasileira de Zoologia 17(1): 157-173.

Jeppson, L. R.; H. H. Keifer \& E. W. Baker. 1975. Mites injurious to economic plants. Berkeley, University of California Press, xxiv + $614 p$.

King, C. B. R. 1937. Notes of the life history of Eriophyes carinatus Green. Bulletin of Entomological Research 28: 311-314.

Oldfield, G. N.; R. F. Hobza \& N. Wilson. 1970. Discovery and characterization of spermathophores in the Eriophyoidea (Acari). Annals of the Entomological Society of America 63 (2): 520 526.

Oldfield, G. N. \& K. Michalska. 1996. Spermatophore deposition, mating behavior and population mating structure, p.185-198. In: E. E. Lindquist; M. W. SABelis \& J. BRuin (eds.). Eriophyoid mites: their biology, natural enemies and control. Amsterdan, Elsevier, xxxiii+643p.

Tanzini, M. R; S. B. Alves; M. A. Tamai; G. J. Moraes \& N. J. Ferla. 2000. An epizootic of Calacarus heveae (Acari: Eriophyidae) caused by Hirsutella thompsoni on rubber trees. Experimental and Applied Acarology 24: 141-144.

Van der Merve, G. G. \& T. J. Coates. 1965. Biological study of the grey mite Calacarus citrifolii Keifer. South Africa Journal of Agricultural Science 8: 817-824.

Vieira, M. R. \& E. C. Gomes. 1999. Sintomas, desfolhamento e controle de Calacarus heveae Feres. 1992 (Acari:Eriophyidae) em seringueira (Hevea brasiliensis Muell. Arg.). Cultura Agronômica 8 (1): 5371. 